\title{
THE SADDle PROSTHESIS FOR SALVAGE OF THE DESTROYED ACETABULUM
}

\author{
E. NIEDER, R. A. ELSON, E. ENGELbRECHT, M. R. KASSELT, A. KELlER, K. STEINBRINK
}

From the EndoKlinik, Hamburg, West Germany

\begin{abstract}
We report the 12 to 74 month results of our mark I saddle prosthesis after its use as a salvage device for gross loss of pelvic bone stock in $\mathbf{7 6}$ patients with failed hip arthroplasties. The implant transmits load between iliac bone and bare polished chrome-cobalt. Our clinical and radiological results indicate that a useful and stable articulation can be achieved in most cases, provided that continued deep infection can be avoided. The appearance of radiological sclerosis at the bearing site in successful cases seems to indicate that significant late migration will not occur.

Based on our experience with the mark I prosthesis we have designed and developed a mark II model which has freedom of axial rotation of the saddle. Our early results in $\mathbf{4 0}$ cases show a significant improvement over the results which could have been predicted for the mark I device.
\end{abstract}

The saddle prosthesis provides a means of establishing a stable and mobile articulation between the femur and a damaged pelvis in which there is no possibility of inserting a conventional hip arthroplasty implant. It provides a saddle-shaped chrome-cobalt surface which bears directly against bone. It may be indicated following excision for tumour or after extensive destruction of bone stock in certain failed hip arthroplasties; the only alternative treatments would be amputation, a pseudarthrosis, or massive bone grafting.

The idea and the design of the mark I pattern of prosthesis (Fig. 1) came from observation of two cases of failed arthroplasty, in which, despite loss of the entire floor of the acetabulum, there was a painless articulation between the neck of the femoral prosthesis and the roof remnant (Fig. 1a). This gave a poor range of movement,

E. Nieder, MD

E. Engelbrecht, MD

K. Steinbrink, MD

EndoKlinik, Holstenstrasse 2, 2000 Hamburg 50, West Germany.

R. A. Elson, FRCS, Consultant Orthopaedic Surgeon

Northern General Hospital, Herries Road, Sheffield S5 7AU, England.

M. R. Kasselt, MD

Missouri Bone and Joint Clinic, 3165 McKelvey Road, Suite 100, St. Louis, Missouri 63044, USA

A. Keller, Engineer

Fa. W. Link, Berghausenweg 10, 2000 Hamburg 63, West Germany.

Correspondence should be sent to Dr med. E. Nieder.

(C) 1990 British Editorial Society of Bone and Joint Surgery

$0301-620 X / 90 / 6200 \$ 2.00$

J Bone Joint Surg [Br] 1990; 72-B: 1014-22. but a stable situation (Nieder and Engelbrecht 1982; Nieder et al 1983a; Nieder 1987).

We now describe the design and medium-term results of the mark I saddle prosthesis and discuss the mark II design, which has a short follow-up but which embodies some improvements. We must emphasise that this prosthesis is advocated only for the extreme types of case mentioned; these are only likely to be encountered in centres dealing with the complications of hip replacement surgery or with tumours of the pelvis; the indications are very rare.

\section{DESIGN AND METHODS}

Severe destruction or resection of pelvic bones may leave only the upper part of the ilium; there may be complete loss of continuity with the lower parts of the pelvis. Above the acetabulum, the remnant of the ilium forms a rapidly tapering pyramidal shape. Superomedially the cortical bone thickens, and its surfaces become confluent; more laterally, this cortical bone is much thinner. We aim to obtain direct bearing above the acetabulum on this thicker medial part of the iliac wing.

In the mark I design, the bearing surface had a smooth saddle, with a narrow and blunt medial horn which could intrude safely into the true pelvis and resist outward displacement. The lateral horn was broader. The saddle was rigidly mounted on a bayonet-shaped neck, offset posterolaterally, and tapered to a straight stem for implantation into the femoral shaft. The offset allowed space for the greater trochanter, but introduced 


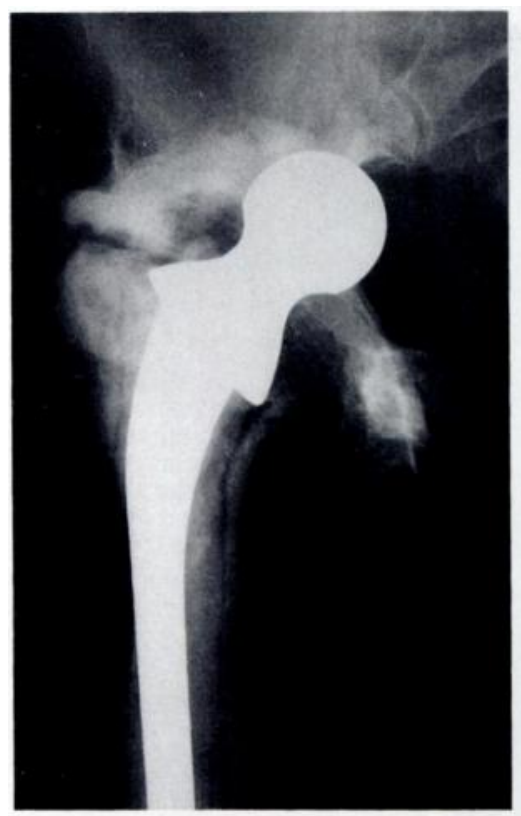

Fig. 1a

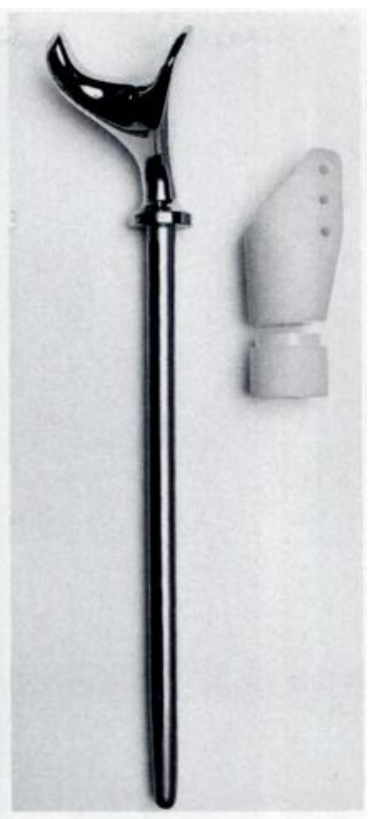

Fig. 1b

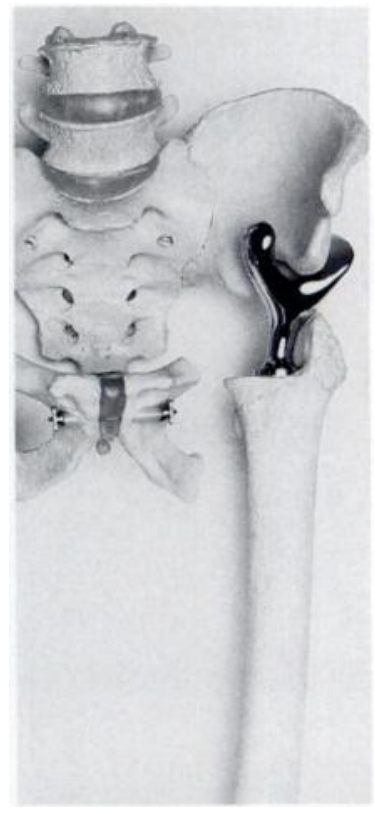

Fig. 1c

Figure la - Radiograph of hip arthroplasty in which the socket had been removed for loosening and central migration. A bearing interface had developed between the ilium and the neck of the prosthesis. Figures $1 \mathrm{~b}$ and Ic - This observation led to the development of the mark I saddle prosthesis. Note the medialisation of the femoral shaft and the consequent short abductor lever arm.

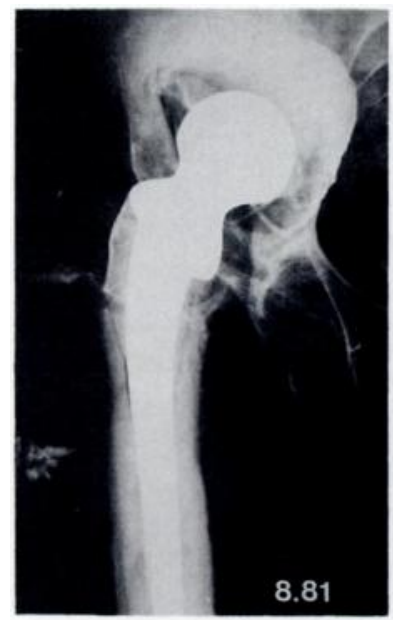

8.81

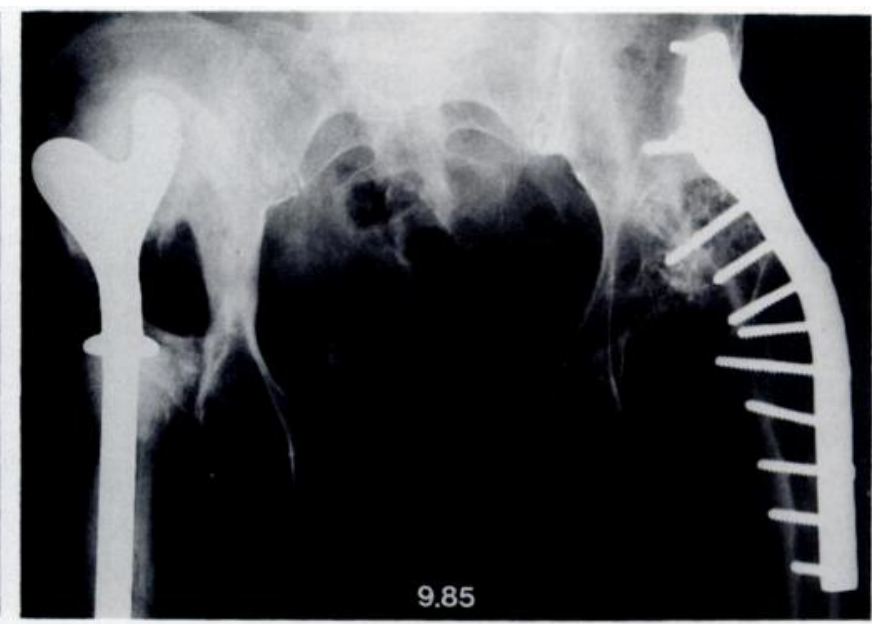

Fig. 2

Pre- and postoperative radiographs of a patient having a saddle arthroplasty after the central migration of the acetabular component of a previously revised arthroplasty. Pre-operative infection had been controlled.

the need for right and left models. The straight stem permitted anteversion of the saddle when this was necessary. Plastic washers placed below the small collar on the stem allowed a choice of correct length during cementing, to compensate for pelvic or femoral bone loss.

In special circumstances involving loss of femoral bone stock, the saddle prosthesis could be adapted to provide total femoral replacement (Engelbrecht and Engelbrecht 1974; Steinbrink, Engelbrecht and Fenelon 1982) and even a total axially-rotating knee replacement (Engelbrecht et al 1981). A comprehensive modular system for total femoral replacement became available early in the development of the mark I saddle (Nieder, Steinbrink and Engelbrecht 1983b); this allowed the surgeon more security with regard to unexpected findings at operation. The comprehensive modular system of the mark II design is discussed later.

Operative technique. The operative technique is straightforward and logical, having been changed little since the introduction of the mark II model. The surgical approach varies according to the case but must provide adequate exposure of the margins of the ilium which remain after tumour resection or, in revision cases, the whole depth of the region of a destroyed acetabulum. In the latter cases, there is almost always a central perforation (Fig. 2). If 

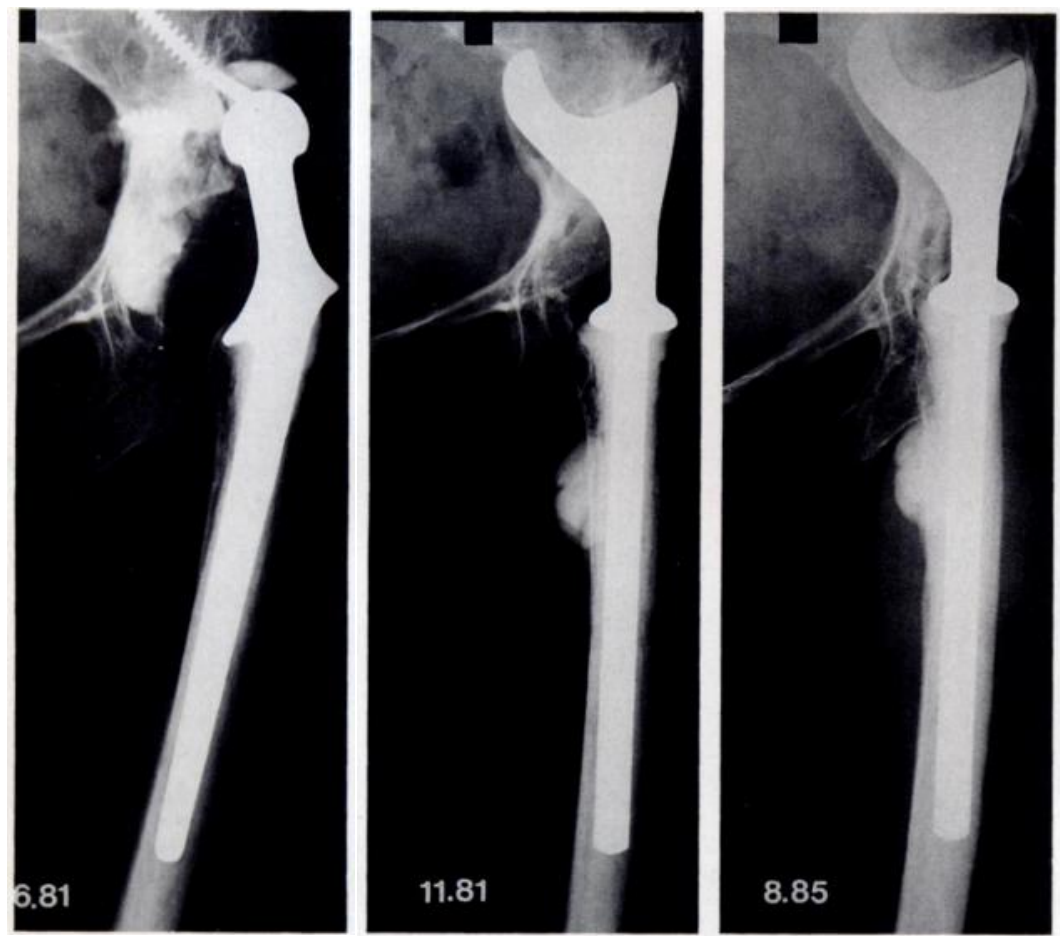

Pre- and postoperative radiographs of a saddle arthroplasty after lateral dislocation of an acetabular component. A medial trap-door has been fashioned; in the later radiograph, healing has occurred and the medial horn of the saddle has become enclosed. not, then one must be made: most safely by making a trap-door hinged inferiorly and driven internally (Fig. 3).

If the pelvic ring is disrupted, the conditions are similar to those after tumour resection. Soft tissues are stripped with great care from the medial cortex, with due awareness of the proximity of the iliac vessels. The available margins of the inner cortex of the ilium are defined and then fashioned into a curved shape superiorly so as to match that of the saddle. The notch so created may be either in the roof of the acetabular remnant or higher; it is essential to ensure that adequate anterior and posterior margins remain to provide stability for the saddle during flexion and abduction; the depth of the notch is that of the saddle. Alignment will vary according to the height of the notch: thus at the level of the old roof the notch is sagittal and the saddle is located in the coronal plane (see Fig. 3), whereas at a progressively higher level it becomes more and more externally rotated (see Fig. 2). Trial insertion of the saddle enables the operator to check length and alignment, stability, and freedom of movement without impingement. The reduction should be firm, not tight, and dislocation should be difficult in all directions. The femoral shaft is usually reamed to a size to allow cement fixation.

After a tumour resection, often with loss of muscle and fascia, stability may be a problem: to maintain sufficient tension and stability, 1 or $2 \mathrm{~cm}$ of overlengthening may be necessary and acceptable.

Postoperative care. In non-infected cases with good abductor attachment, partial weight-bearing with crutches can start after a few days bed rest. Extensive loss of soft tissue requires support from a half-leg plaster
Table I. Details of 76 mark I saddle arthroplasties performed for failure of previous total hip replacement

\begin{tabular}{|c|c|}
\hline Age of patients (in years) & 32 to 84 \\
\hline \multicolumn{2}{|l|}{ Original diagnosis } \\
\hline Osteoarthritis & 28 \\
\hline Dysplasia & 19 \\
\hline Rheumatoid arthritis & 13 \\
\hline Fracture neck of femur & 9 \\
\hline Fracture-dislocation of hip & 3 \\
\hline Tuberculosis & 2 \\
\hline Ankylosing spondylitis & 2 \\
\hline Infected at time of operation & 33 \\
\hline With previous history of infection & 11 \\
\hline Not infected at time of operation & 28 \\
\hline Pseudarthrosis & 13 \\
\hline Pelvic ring disruption & 24 \\
\hline Arthrodesis of opposite hip & 3 \\
\hline Simple saddle arthroplasty & 55 \\
\hline Saddle with proximal femoral replacement & 6 \\
\hline Saddle with total femoral and knee replacement & 11 \\
\hline Bilateral cases (6 hips) & 3 \\
\hline Patients lost to follow-up & 4 \\
\hline Hips available for follow-up & 72 \\
\hline Failure due to continued infection & 13 \\
\hline Failure due to new primary infection & 2 \\
\hline $\begin{array}{l}\text { Hips a vailable for functional assessment } \\
\text { at } 12 \text { to } 74 \text { months (mean } 33.5 \text { ) }\end{array}$ & 57 \\
\hline
\end{tabular}

spica for several weeks. If the leg lies in external rotation because of loss of muscle attachments at the proximal femur, an anti-rotation splint is used during bed rest to allow healing in a neutral position.

Active exercises are performed with due care: the patient must understand that strength cannot approxi- 
mate to that after a normal hip replacement. Similarly, using a crutch in the contralateral hand should not be discouraged until the patient is fully confident. No intramuscular injections should be given on the saddle side.

\section{RESULTS}

Table I summarises our experience with the mark I saddle prosthesis for revision of total hip arthroplasty. The problems confronting the surgeons were of exceptional magnitude in all the cases; we cannot present all the problems in detail. Most patients had very extensive loss of bone and soft tissue, all had had multiple operations and some were infected. All prostheses were cemented to the femur, or to the tibia if the whole femur was replaced. Acrylic cement with added antibiotic powder was used for infected cases; most patients had a one-stage procedure.

Table II. Patients' acceptance of their condition before and after saddle arthroplasty

\begin{tabular}{lcc}
\hline & Pre-op & Review \\
\hline Enthusiastic & 0 & 9 \\
Likes & 0 & 5 \\
Accepts & 0 & 35 \\
Dislikes & 57 & 8 \\
\hline
\end{tabular}

We chose Enneking's (1987) method of evaluation because of our increasing use of the method for tumour cases. However, the various parameters have been reported separately and not combined into a total score, so that a detailed evaluation of each case is possible. Figure 4 shows these results for each parameter and the average change from pre- to postoperative levels for each.

Table III. Function before and after saddle arthroplasty in the 57 patients who could be assessed (see Table I)

\begin{tabular}{|c|c|c|}
\hline & Pre-op & Review \\
\hline Unrestricted & 0 & 1 \\
\hline Minor restrictions & 0 & 21 \\
\hline Partial disability & 15 & 29 \\
\hline $\begin{array}{l}\text { Able to get out of bed, } \\
\text { perform personal hygiene } \\
\text { and move a few yards }\end{array}$ & 21 & 4 \\
\hline Completely dependent & 21 & 2 \\
\hline
\end{tabular}

Movement refers to the passive range at the hip alone, without any contribution from the lumbar spine. Rotation in the long axis of the limb was nearly always restricted, and flexion and abduction were reduced. All patients, including those with bilateral saddle prostheses, could sit satisfactorily.

Pain was consistently relieved. Axial loading rarely gave any pain, but there was often some discomfort on rotation in the long axis of the limb. No patient had significant sacro-iliac symptoms, even when the pelvic ring was disrupted.

Stability tests showed a negative Trendelenburg sign in 16 hips. Where there were abductor deficiencies, a block to adduction was achieved by the impingement of the lesser trochanter against the ischium. In only one case, mentioned later, was this painful. No patient developed a significant fixed contracture, but it was impossible to correct fully the pre-operative loss of leg length and/or contracture in about half the cases because of soft-tissue scarring.

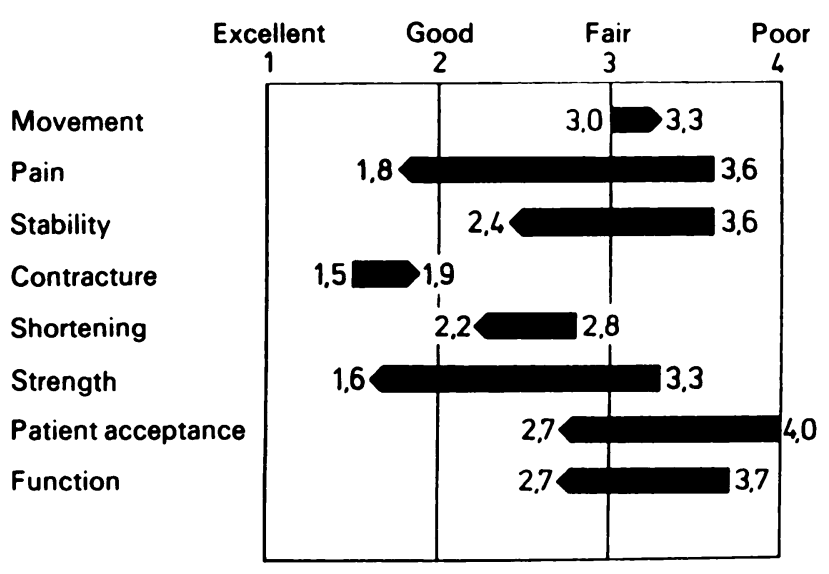

Fig. 4

Average changes after saddle arthroplasty according to various parameters.

Strength had been significantly improved because of the relief of pain and the provision of a stable pivot.

The patients' acceptance of the result and the level of functional activity correlated closely; we considered that these were the most important parameters. The average improvement was only from poor to fair but this produced a marked improvement in social status and the quality of life - often after years of total dependency. Excluding the 13 cases of continued infections and the two newly infected cases, only two other patients remained bedridden as compared with 21 who were totally dependent and uninfected before the operation (Tables II and III). 
Complications are listed in Table IV. In particular, it should be noted that 13 of the 33 cases treated for existing deep infection remained uncured and had continued sepsis. Two patients with previously sterile failure subsequently became infected. These 15 patients all had poor results because of the infection; they have been excluded from the functional assessment because we wished to draw attention to the potential of the noninfected saddle prosthesis. Four patients were lost to follow-up and two died from unrelated causes.
Migration and bone reaction. Some upward migration of the saddle was seen in all cases, but in most this soon stabilised. In several cases, however, migration continued; this is shown graphically in Figure 5. Analysis of this aspect showed that:

1) Uninfected cases with radiological sclerosis at the interface stabilised after a short period of migration (Fig. 6). This migration probably represented the early 'bedding-in' of the saddle.

2) Deep infection led to progressive migration. This was

Table IV. Complications in 76 saddle arthroplasties

\begin{tabular}{|c|c|c|}
\hline & Number & Management \\
\hline None & 44 & \\
\hline $\begin{array}{l}\text { Deep infection } \\
\text { Persisting (of 33) } \\
\text { New }\end{array}$ & $\begin{array}{r}13 \\
2\end{array}$ & $\begin{array}{l}\text { Disarticulation } 6 \\
\text { Pseudarthrosis } 6 \\
\text { Exploration sinus } 1 \\
\text { Awaiting revision } 1 \\
\text { Died 1 }\end{array}$ \\
\hline \multicolumn{3}{|l|}{ Technical error } \\
\hline $\begin{array}{l}\text { cortices of ilium) } \\
\text { Rotatory instability (incorrect fixation of stem } \\
\text { locking mechanism) }\end{array}$ & 1 & Corrective operation \\
\hline $\begin{array}{l}\text { Pain and poor movement due to tight insertion of } \\
\text { over-long prosthesis }\end{array}$ & 1 & Accepted \\
\hline $\begin{array}{l}\text { Femoral loosening with fracture femur (stem too } \\
\text { short for weak proximal femur) }\end{array}$ & 1 & Total femoral replacement \\
\hline \multicolumn{3}{|l|}{ Prosthesis-related complications } \\
\hline Postoperative central dislocation & 1 & Closed reduction \\
\hline Painful impingement against ischium & 1 & Local excision \\
\hline Spiral fracture of distal femur & $i$ & Plating fracture \\
\hline $\begin{array}{l}\text { Femoral loosening } \\
\text { Static }\end{array}$ & 2 & Continue obseryation \\
\hline Progressive & 1 & $\begin{array}{l}\text { Exchanged } \\
\text { Extion }\end{array}$ \\
\hline Traumatic fracture iliac wing & 1 & Pseudarthrosis \\
\hline Spontaneous fracture iliac wing & $i$ & Pseudarthrosis \\
\hline Recurrent dislocation & 1 & Repeated reduction \\
\hline
\end{tabular}

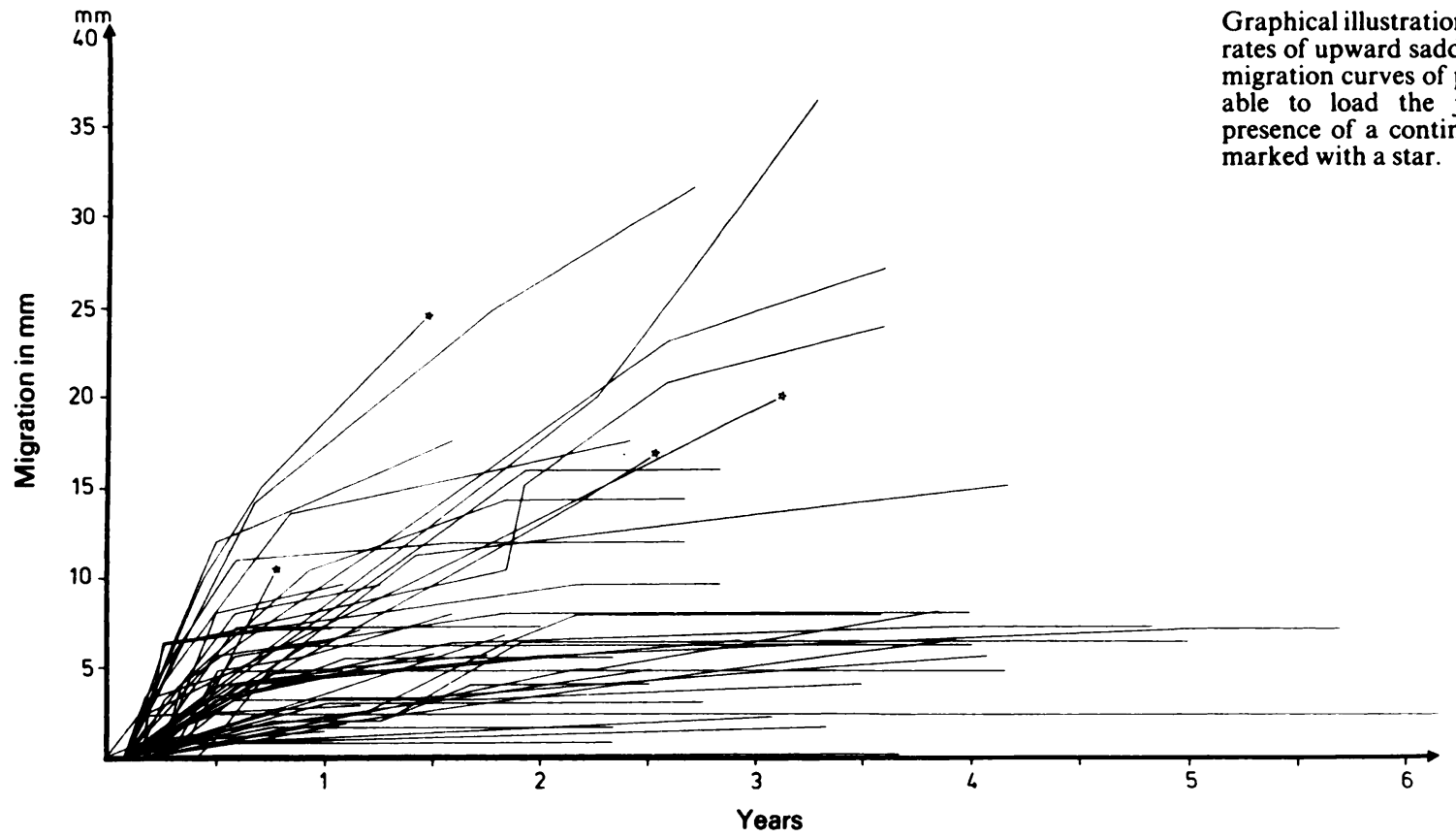

Fig. 5 
clearly demonstrated in four cases in which pain was minimal despite continued infection so that the patient was able to load the joint. Where loading was impossible migration did not occur (Fig. 7), even in the presence of infection.

3) When bone sclerosis was absent or minimal, even in sterile cases, progressive migration nearly always occurred.

4) The development of shelves of new bone in contact
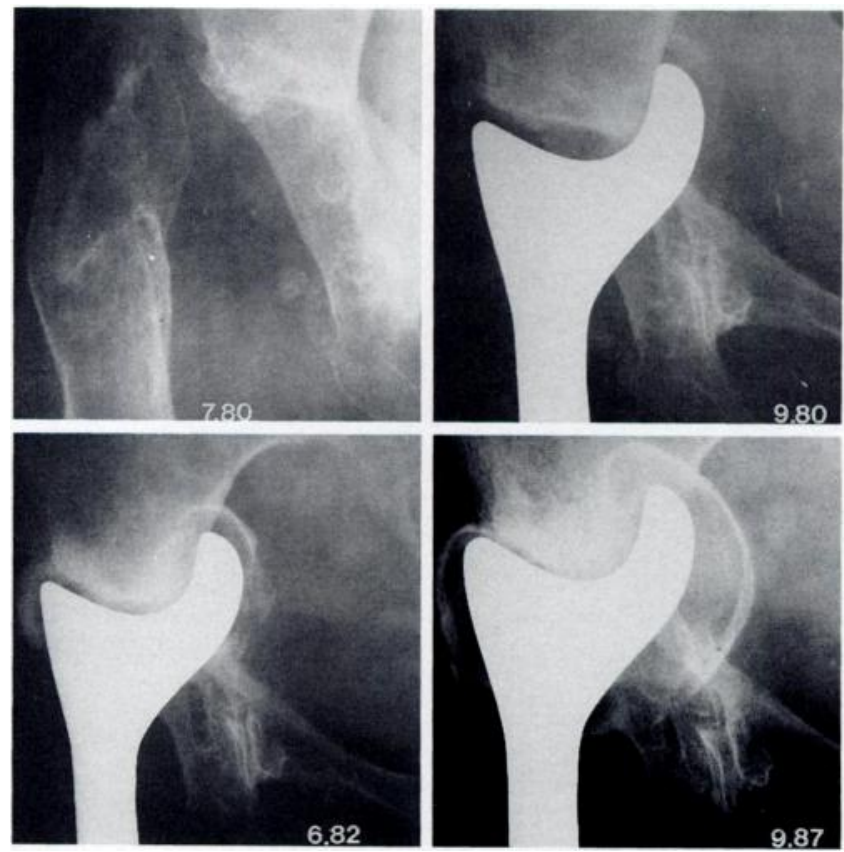

Fig. 6

Radiographs showing the postoperative appearances of a saddle arthroplasty with good bone sclerosis. There has been negligible upward migration during seven years, despite vigorous function. with the horns of the saddle was seen mostly in cases with marked sclerosis and little tendency to migrate (see Fig. 6).

We could not relate the rate of migration to osteoporosis, the pre-operative diagnosis, the site of implantation, the degree of activity, nor the integrity of the pelvic ring.

\section{DISCUSSION}

The direct application of load and movement between metal and bone has uncertain consequences. The abnormal articulation at the saddle could have resulted in progressive erosion in all cases, but we found that, in most patients, a brief period of migration led to radiological sclerosis and satisfactory stabilisation.

In some of our cases there had been total loss of continuity of the upper and lower parts of the pelvis. This meant that the application of load to the isolated segment of the ilium could have led to intolerable forces at the sacro-iliac joint, but in practice this caused no problems.

Our unsatisfactory results were associated with either poor function due to limited range of movement, poor abductor strength or discomfort during axial rotation, or with early failure due to progressive upward migration, pelvic wing fracture, loosening or fracture of the femur. All these problems could be related to the rigid nature of the system. The mark I saddle was rigidly mounted to the femoral component; its rotation was restricted. The femoral offset was small and depended on the rotatory alignment of the saddle in relation to the direction of the iliac notch. The load-bearing surface was narrow. Compensation for pelvic bone loss could be achieved only by femoral elongation, and the system was not modular.
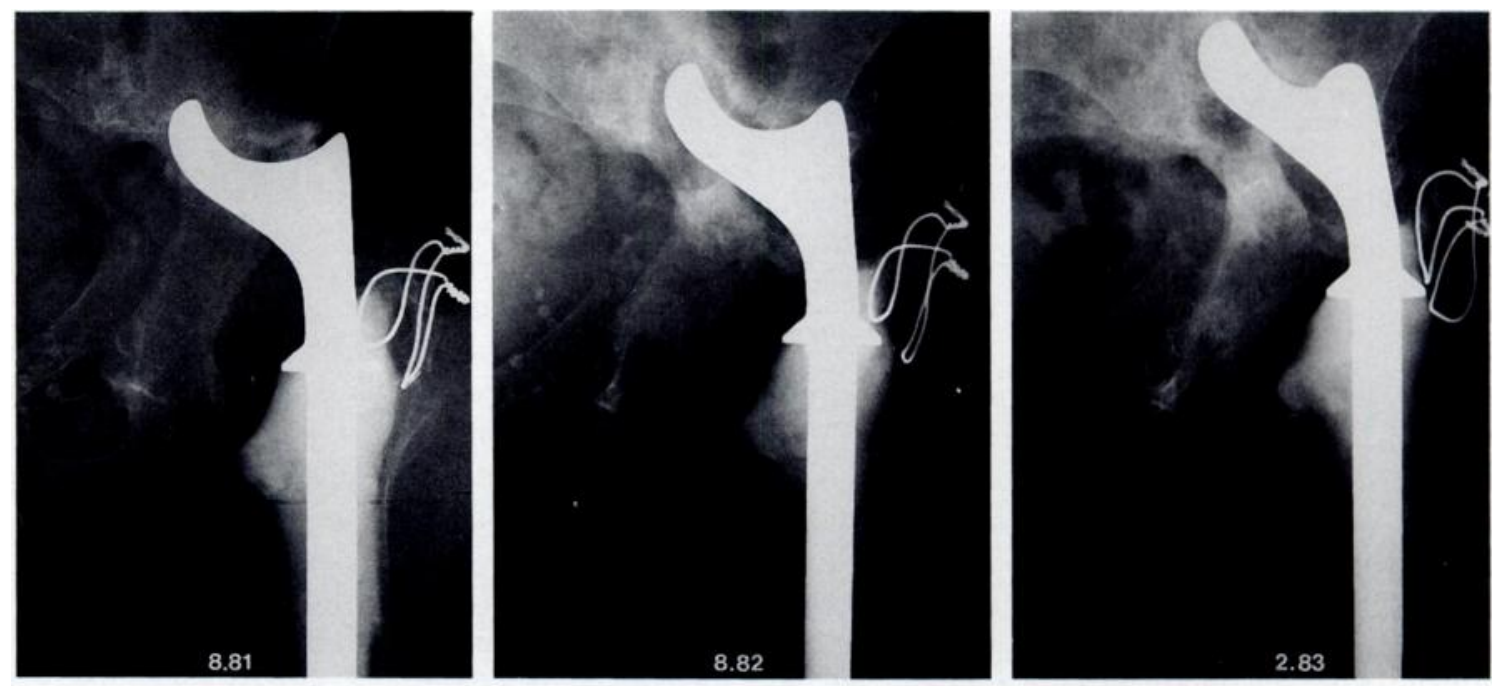

Fig. 7

Radiographs showing the postoperative appearances of a saddle arthroplasty with progressive migration due to infection. The hip was not painful and had been loaded throughout. 
Five modifications were introduced in the mark II saddle prosthesis to correct these factors.

1) Freedom of rotation. The mark I design was a pure saddle allowing only two directions of unconstrained movement. A few degrees of rotation in the long axis of the femur were possible, but further rotation depended on an unscrewing separation at the saddle. The resultant restriction of rotation may have been the main reason for poor range of movement and discomfort, as well as a cause for disordered stress and high torsional load on weak pelvic and femoral bone.

Clearly, the saddle would function best if it was allowed to follow its own trajectories of motion; an additional articulation was therefore introduced, with freedom of movement at right angles to the load-bearing axis. This can allow any required rotation (Fig. 8).
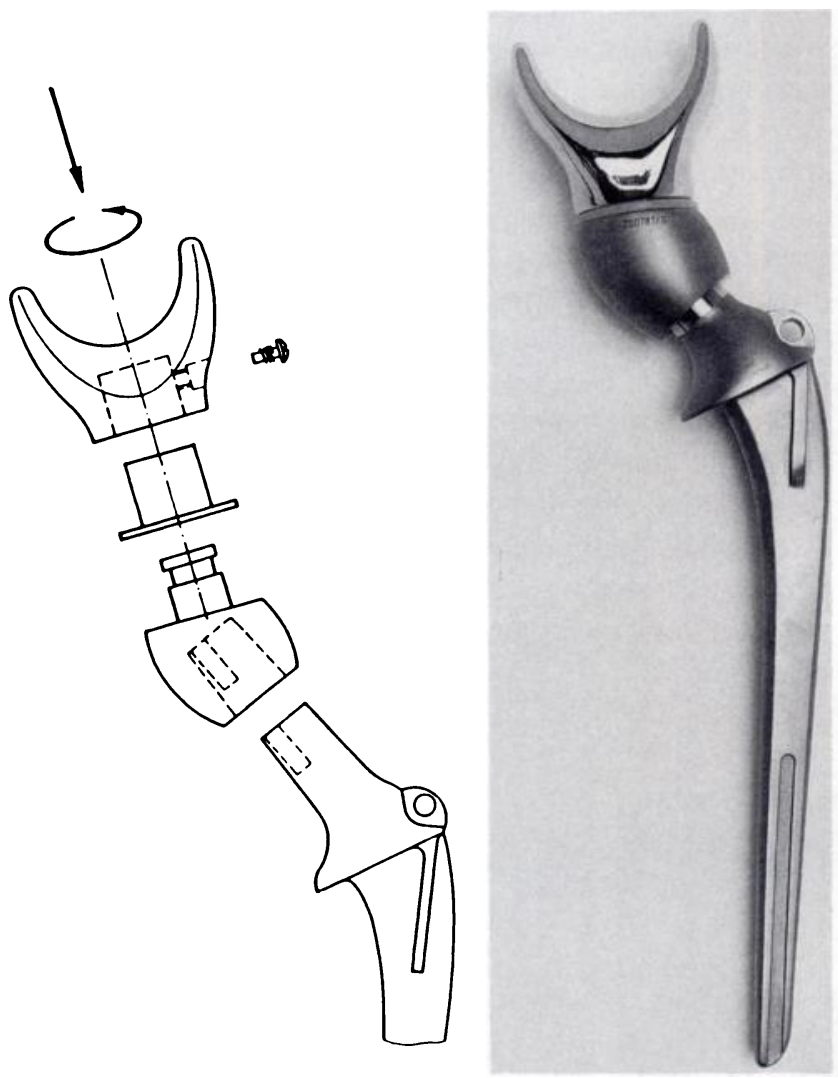

Fig. 8

The mark II saddle prosthesis with its axial rotating bearing. The abductor lever arm has been significantly lengthened.

2) Increased femoral offset. The abductor lever arm provided by the mark I saddle was short. For a given abductor muscle strength, the loading of the bone at the interface was therefore relatively high (see Fig. 1). In addition, in many cases, available muscle strength had been reduced by partial detachment or other damage; poor abductor function was to be expected.
The increased offset provided in the mark II model augments the abductor lever arm, increases abductor efficiency, and improves the load-bearing characteristics of the saddle. The femur is in a more physiological alignment; increased offset and freedom of axial rotation must improve the function of all the remaining muscle groups around the hip. Impingement is less likely and medialisation of the site of the joint is possible.

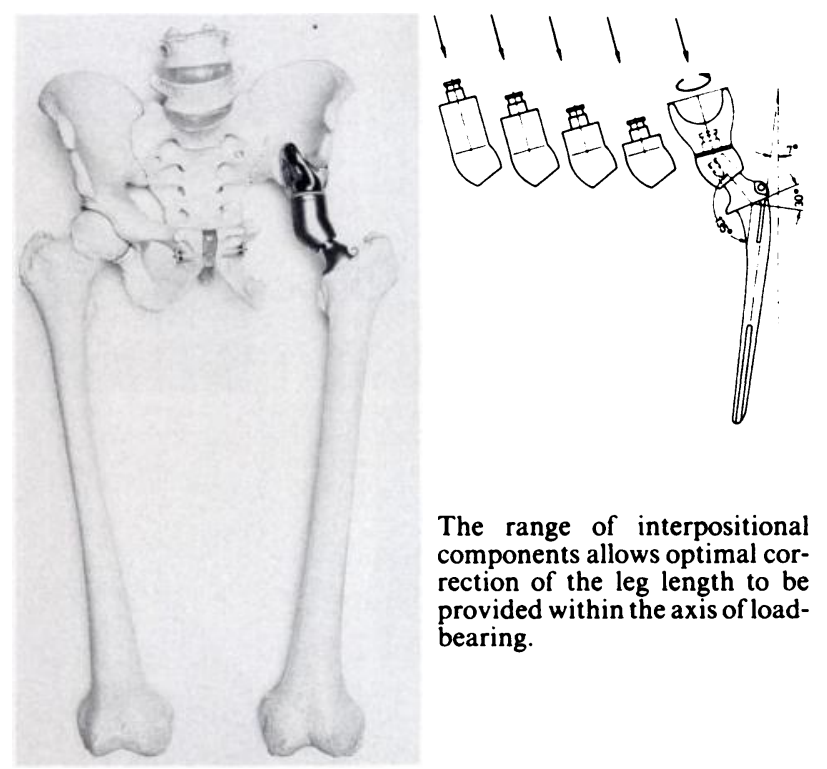

Fig. 9

3) A broader saddle. The narrow load-bearing surface of the mark I saddle was provided so as to allow a few degrees of axial rotation. In the mark II prosthesis, the new freedom of axial rotation allows the use of a broader saddle which distributes load over a larger area. This leads to a reduction in unit pressure and may show a reduced tendency to upward migration.

4) Correction of leg-length. Compensation for major pelvic bone loss with the mark I saddle was achieved by placing plastic washers below the collar in the femoral axis. In the mark II design, the modular components allow the optimal tensioning of soft tissue by correction of length in the load-bearing axis (Fig. 9). This elongation is therefore related to the pelvic side while the relative offset is preserved. This gives a further important advantage in that the site of the saddle can be medialised as far into the denser iliac bone as is necessary.

5) Modular use. The mark II saddle has a conical mounting (Figs 8 and 9) which allows easy attachment to any of the various femoral components. This mounting includes a drill hole and pin which mate to prevent rotation at the cone. The conical mounting also allows future re-conversion to a ball and socket joint if pelvic reconstruction becomes possible after the control of 


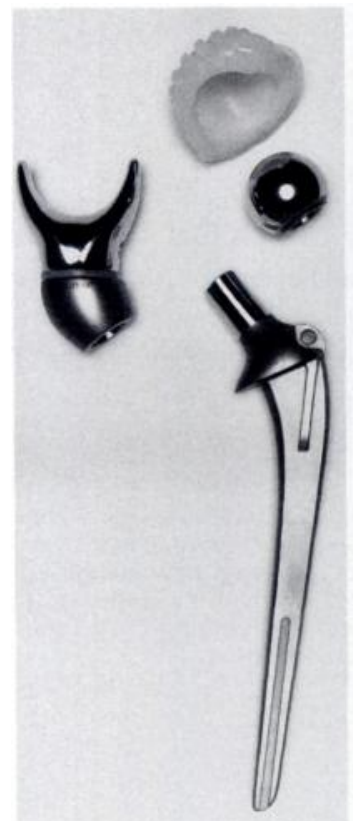

Fig. 10a

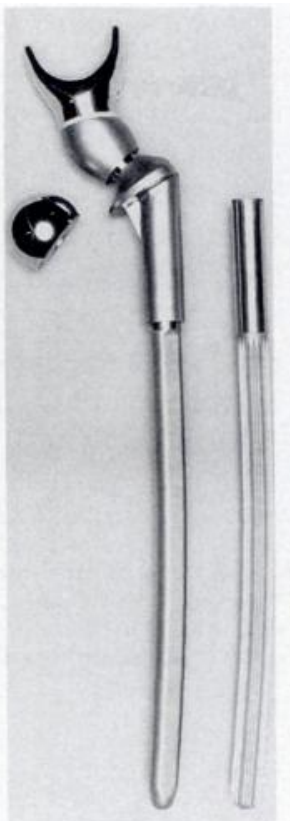

Fig. 10b

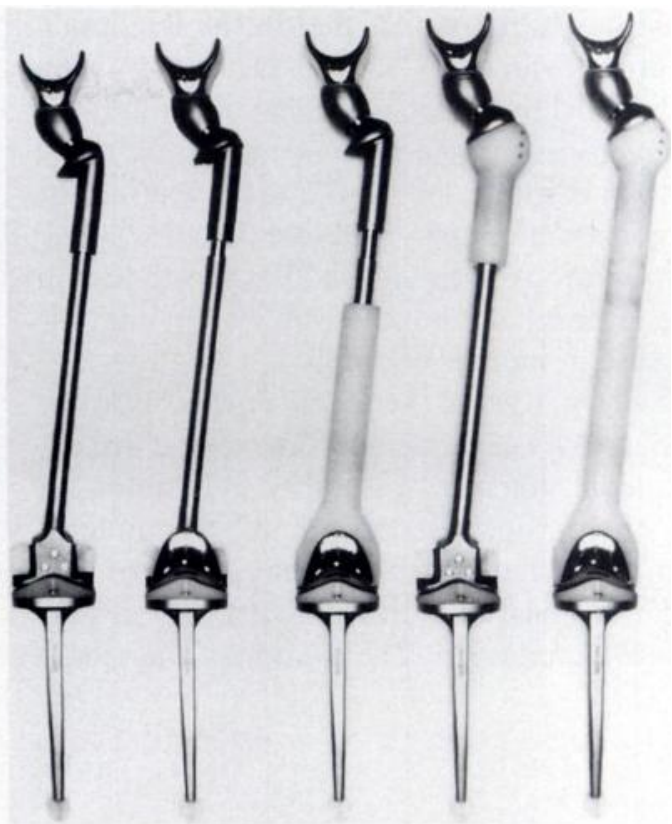

Fig. 10c

The modular system of the mark II saddle prosthesis showing the range of possibilities including: (a) the regular anatomical stem; (b) the systems for cementless reconstruction and cemented revision for major proximal femoral bone loss; and (c) various types of total femoral replacement. The conical mounting on the femoral stems allows for possible future conversion back to a conventional hip arthroplasty should acetabular reconstruction become feasible.

The radiographic and clinical result seven months after a mark II saddle arthroplasty for failure of a previous hip replacement. Active hip flexion is satisfactory, and axial rotation in extension is markedly better than that experienced with the mark I saddle.
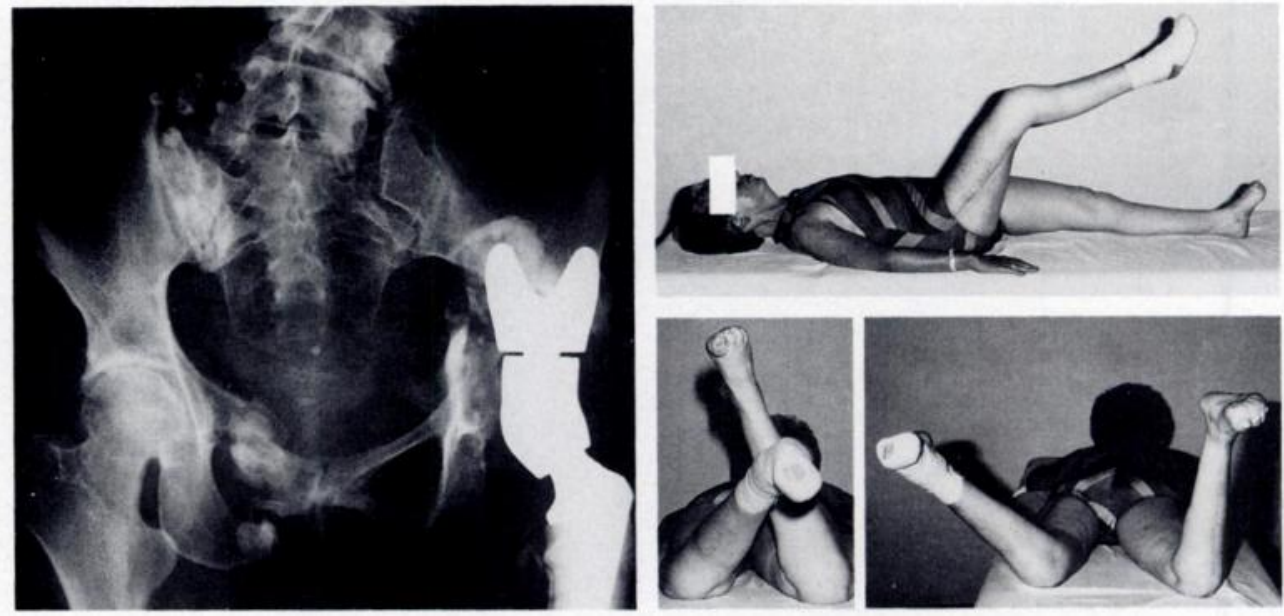

Fig. 11

infection or tumour. Figure 10 shows the range of possibilities for dealing with progressively more severe loss of bone stock.

Our experience with the mark I prosthesis after follow-up of from 12 to 74 months has given us an accurate picture of its clinical behaviour. The early functional results with the mark II prosthesis are much better; we see no reason to suspect that these will fail sooner or to a greater degree than have the mark I prostheses. The increased movement allowed by the new system can be seen and felt on examination of the patient (Fig. 11). In the first 40 mark II hips, pain is less frequent and range of movement and muscle control are better. The longest follow-up, however, is only 28 months and although the difference in early function is definite, longer-term results must be awaited.

Saddle arthroplasty is a salvage procedure : its results cannot compare favourably with those of conventional hip arthroplasty. The strictness of our indications for the use of this prosthesis in the revision of total hip 
arthroplasty is shown by the fact that in the five and a half years during which 76 saddle prostheses were implanted, almost 3000 standard exchange total hip arthroplasties were performed at the EndoKlinik (2079 in aseptic and 916 in infected cases). The proven success of allograft reconstruction for acetabular deficiency may reduce the indications for the saddle prosthesis in uninfected hip arthroplasty, but there may be an increase in its potential use in surgical oncology.

The main alternatives to the saddle prosthesis in our complex revision cases are a pseudarthrosis or a disarticulation. The saddle offers better stability and restoration of leg-length than a pseudarthrosis. If the failures resulting from continued infection, technical error and design-related complications are excluded, our results appear to be well maintained. The loading of the saddle is more rigid than that of the compliant soft-tissue loading of a pseudarthrosis, which is known to last indefinitely. However, a pseudarthrosis is unlikely to function well if more than $5 \mathrm{~cm}$ of bone stock has been lost, and the level of discomfort is unpredictable. The saddle prosthesis, in its modular form, can compensate for much greater losses of bone stock and can be adapted for upper femoral or total femur replacement; undoubtedly, even in our mark I series, these features have enabled us to save limbs.

Although none of the authors have received or will receive benefits for personal or professional use from a commercial party related directly or indirectly to the subject of this article, benefits have been or will be received but are directed solely to a research fund, foundation, educational institution, or other non-profit institution with which one or more of the authors is associated.

\section{REFERENCES}

Engelbrecht E, Engelbrecht $\mathbf{H}$. Totalersatz des Femurs unter Verwendung der Hüft- und Kniegelenkstotalendoprothesen, Modell "St. Georg". Chirurg 1974; 45:231-6.

Engelbrecht E, Nieder E, Strickle E, Keller A. Intracondyläre Kniegelenksendoprothese mit Rotations-möglichkeit - Endo Modell. Chirurg 1981; 52:368-75.

Enneking WF. A system for the functional evaluation of the surgical management of musculoskeletal tumors. In: Enneking WF, ed. Limb salvage in musculoskeletal oncology. Edinburgh: Churchill Livingstone, 1987:5-16.

Nieder E. Die Sattelprothese. In: Endo-Klinik, ed. Primar- und Revisions- Alloarthroplastik Huft- und Kniegelenk. Berlin, etc: Springer, 1987:257-71.
Nieder E, Engelbrecht E. Die Sattelprothese, eine Alternative in Grenzsituationen des alloplastischen Hüftgelenkersatzes. In: Wolter D, ed. Osteolysen - pathologische Frakturen. Paul-SudeckSymposium in Hamburg 1981. Stuttgart, etc: Georg Thieme, 1982:324-31.

Nieder E, Engelbrecht E, Steinbrink K, Keller A. Modulares System für den Femurtotalersatz - Endo-Modell. Chirurg 1983a; 54: 391-9.

Nieder E, Steinbrink K, Engelbrecht E. Sattelprothese und totaler Femurersatz. Der Krankenhausarzt 1983b; 56:498-504.

Steinbrink K, Engelbrecht E, Fenelon GCC. The total femoral prosthesis: a preliminary report. J Bone Joint Surg [Br] 1982; 64-B: 305-12. 